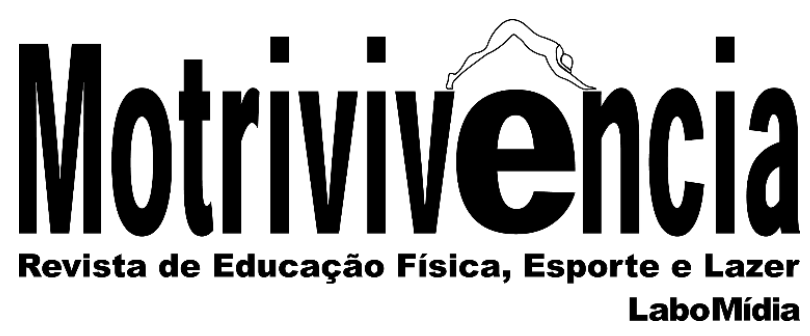

\title{
Era uma vez um ministério do esporte...: seu financiamento e gasto nos governos Lula, Dilma e Temer
}

\section{RESUMO}

O texto tem como objetivo analisar o financiamento e gasto do Ministério do Esporte de 2003 a 2018, tendo por base os Governos Lula, Dilma e Temer. O estudo tem caráter quantitativo-qualitativo e se apoiou em levantamento documental, tendo sido analisado três indicadores sobre o financiamento e gasto com esporte. Em relação ao indicador fontes de financiamento identificamos que a maior parte do financiamento do Ministério do Esporte foi de recursos ordinários. No indicador magnitude do gasto ficou claro que a maior parte dos recursos autorizados no período foram contingenciados e os recursos gastos tiveram grande variação no período. $\mathrm{O}$ indicador de direção do gasto demonstrou que a maioria do gasto foi com Infraestrutura e Megaeventos esportivos, no Governo Lula a prioridade foi com Infraestrutura, no Governo Dilma foi com Megaeventos esportivos e no Governo Temer foi com Gestão e Infraestrutura.

PALAVRAS-CHAVE: Políticas públicas;

Orçamento público; Financiamento do esporte; Ministério do esporte
Fernando Henrique Silva Carneiro

Doutor em Educação Física-UnB Instituto Federal de Goiás-UFG

Senador Canedo, Goiás, Brasil fernandohenriquesc@gmail.com https://orcid.org/0000-0002-2800-1895

\section{Pedro Fernando Avalone Athayde \\ Doutor em Política Social-UnB \\ Universidade de Brasília-UnB \\ Faculdade de Educação Física \\ Brasília, Distrito Federal, Brasil pedroavalone@gmail.com \\ (D) https://orcid.org/0000-0002-1825-0097}

Fernando Mascarenhas

Pós-Doutorado em Política Social-UERJ

Universidade de Brasília-UnB

Faculdade de Educação Física

Brasília, Distrito Federal, Brasil

fernandom@unb.br

https://orcid.org/0000-0002-1825-0097 
Once upon a time there was a ministry of sports ...: its financing and spending in the Lula, Dilma and Temer governments

\begin{abstract}
The text aims to analyze the financing and spending of the Ministry of Sports from 2003 to 2018, based on the Lula, Dilma and Temer Governments. The study has a quantitative-qualitative character and was supported by a documentary survey, having analyzed three indicators on financing and spending on sports. Regarding the sources of financing indicator, we identified that most of the financing of the Ministry of Sport was from ordinary resources. In the magnitude of spending indicator, it was clear that most of the funds authorized in the period were provisioned and resources spent have had great variation in the period. The spending direction indicator showed that most of the spending was with Infrastructure and Sports Mega-events, in the Lula Government the priority was with Infrastructure, in the Dilma Government was with Sports Mega-events and in Government Temer was with Management and Infrastructure.
\end{abstract}

KEYWORDS: Public policies; Public budget; Sports financing; Sport ministery

Era una vez un ministerio del deporte ...: su financiamiento y gasto en los gobiernos Lula, Dilma y Temer

\title{
RESUMEN
}

El texto tiene como objetivo analizar el financiamiento y gasto del Ministerio del Deporte de 2003 a 2018, teniendo como base los Gobiernos Lula, Dilma y Temer. El estudio tiene carácter cuantitativo-cualitativo y se apoyó en el levantamiento documental, habiendo sido analizado tres indicadores sobre el financiamiento y gasto con deporte. En relación al indicador fuentes de financiamiento identificamos que la mayor parte de la financiación del Ministerio del Deporte fue de recursos ordinarios. En el indicador magnitud del gasto quedó claro que la mayor parte de los recursos autorizados en el período fueron contingenciados y los recursos gastados tuvieron gran variación en el período. El indicador de dirección del gasto demostró que la mayoría del gasto fue con Infraestructura y Megaeventos deportivos, en el Gobierno Lula la prioridad fue con Infraestructura, en el Gobierno Dilma fue con Megaeventos deportivos y en el Gobierno Temer fue con Gestión e Infraestructura.

PALABRAS-CLAVE: Políticas públicas; Presupuesto público; Financiamiento del deporte; Ministerio del deporte 


\section{INTRODUÇÃO}

O Ministério do Esporte (ME) foi criado em 2003 no início do Governo presidido por Luiz Inácio Lula da Silva (2003-2010), do Partido dos Trabalhadores (PT). Anteriormente a pasta do esporte teve diferentes configurações: Ministério do Esporte e Turismo, Ministério Extraordinário do Esporte, Secretaria de Desportos, Secretaria de Desportos da Presidência da República, Secretaria de Educação Física e Desporto, Departamento de Educação Física e Desportos e Divisão de Educação Física (MINISTÉRIO DO ESPORTE, 2018). Contudo, depois de 16 anos de existência enquanto ministério, em 2019 voltou a ser uma secretaria - Secretaria Especial do Esporte -, estando vinculada ao Ministério da Cidadania, alteração realizada pelo governo presidido por Jair Messias Bolsonaro, do Partido Social Liberal (PSL).

A criação do ME se deu em um contexto de vitória eleitoral de Lula e o PT depois de três derrotas para as eleições presidenciais - 1989, 1994 e 1998. Sua vitória teve um misto de entusiasmo e desconfiança (FRIGOTTO, 2004), entusiasmo por mudanças sociais, engendrado pelo ineditismo da chegava à presidência de um ex-operário, líder sindical e de um partido historicamente localizado no campo da esquerda política. De outro lado, a desconfiança derivava de percepção anterior às eleições de 2002 acerca de um transformismo em Lula e no PT (FILGUEIRAS, 2015), além da criação de ministérios e secretarias pelo novo presidente como forma de ampliar a base de apoio, incluindo o ME. Na produção acadêmica há diferentes interpretações sobre o Governo Lula: um governo neoliberal (COUTINHO, 2010; OLIVEIRA, 2010; BOITO JÚNIOR, 2012a; PINTO, 2015); um governo pós-neoliberal (SADER, 2013); a presença do lulismo e um reformismo fraco - um caso de "grande personalidade" a presidir um governo de coalizão (SINGER, 2012); e com uma perspectiva (neo)desenvolvimentista (BOITO JÚNIOR, 2012a; PINTO et al., 2016).

Nos governos presidenciais subsequente - Dilma Rousseff (2011-2016), do PT, e Michel Temer (2016-2018), do Movimento Democrático Brasileiro (MDB) - o ME se manteve. Diferentes autores (ANDERSON, 2011; SINGER, 2012) apontam que a vitória de Dilma em 2010 foi fruto da influência de Lula, haja vista ser ela uma personagem à época pouco conhecida no meio político e sem qualquer traço carismático de apelo popular, sua ascensão se deu no vácuo de candidatos do PT à presidência. Durante o Governo Dilma identifica-se algumas singularidades como a tentativa de ensaio desenvolvimentista (SINGER, 2015), contudo esse experimento não conseguiu ir a diante, asfixiado por um cenário econômico desfavorável e pela falta de governabilidade e articulação política (PINTO et al., 2016). 
Embora Dilma tenha sido reeleita em 2014, já em 2015 começou uma articulação de forças regressivas e reacionárias apresentando a possibilidade do impeachment de seu Governo, movimento apoiado por Michel Temer. O impeachment foi concretizado e Temer assumiu a presidência, a marca do seu governo foi a implementação de políticas de ajuste fiscal, atendendo aos interesses do capital (CARNEIRO, 2018), como a promulgação da Emenda Constitucional (EM) 95/2016. Além disso, articulou com o Congresso Nacional a contrarreforma trabalhista que flexibilizou e precarizou ainda mais as relações de trabalho e tentou realizar a contrarreforma da previdência.

Starepravo, Mezzadri e Marchi Junior (2015) apontam que o ME foi criado de última hora com a necessidade de acomodar o Partido Comunista do Brasil (PCdoB) - que apoiara o PT em todas as eleições presidenciais anteriores - na nova estrutura ministerial. Na criação do ME, sua estrutura organizacional ficou com quatro Secretarias: a Secretaria Executiva, a Secretaria Nacional de Esporte Educacional (SNEED), a Secretaria Nacional de Esporte de Alto Rendimento (SNEAR) e a Secretaria Nacional de Desenvolvimento do Esporte Recreativo e do Lazer (SNDEL) (BRASIL, 2003). Destas, a gestão da SNDEL foi delegada a quadros ligados ao PT, enquanto as demais ficaram sob responsabilidade do $\mathrm{PCdoB}$ - cabe ressaltar que a convivência entre esses dois partidos no interior do ME foi conflituosa, sendo marcada por divergências políticas e conceituais. Em 2011, no Governo Dilma, o ME passou a ter uma outra configuração organizacional, continuou a Secretaria Executiva e a SNEAR, contudo a SNEED e a SNDEL foram fundidas surgindo a Secretaria Nacional de Esporte, Educação, Lazer e Inclusão Social (SNEELIS), além da criação da Secretaria Nacional de Futebol e Defesa dos Direitos do Torcedor (SNFDDT), estrutura que durou até o final do Governo Temer em 2018.

$\mathrm{O}$ processo de reorganização administrativa do $\mathrm{ME}$ e as distintas perspectivas políticas tiveram reflexo direto sobre a consecução das ações ministeriais na política esportiva nacional. Partimos do princípio que a compreensão do financiamento e gasto é uma chave interpretativa importante para compreender como uma política foi materializada. Existem estudos que tematizaram os recursos orçamentários do $\mathrm{ME}$, a maior parte se dedicou ao período do Governo Lula (ALMEIDA; MARCHI JÚNIOR, 2010; ATHAYDE, 2014; ATHAYDE; MASCARENHAS; SALVADOR, 2015; CASTRO, 2016;), há os que estudaram os Governos Lula e Dilma (CARNEIRO, 2018; TEIXEIRA et al., 2018; MASCARENHAS, 2016; FIGUERÔA et al., 2014) e apenas o Governo Dilma (CARNEIRO et al., 2019), porém inexistem estudos que abarquem o Governo Temer. Outros estudos tematizaram programas esportivos específicos dos referidos Governos, como o Programa Bolsa Atleta (TEIXEIRA et al., 2017; CORRÊIA et al., 2014), o 
Programa Segundo Tempo (MATIAS, 2013; CASTRO; SCARPIN; SOUZA, 2017) e o Programa Esporte e Lazer da Cidade (PINTOS, 2017; TEIXEIRA et al., 2014).

Com o fim da presença do esporte com uma pasta ministerial é importante compreender como se materializaram as ações do ME ao longo da sua existência, a partir do seu financiamento e gasto. Análises longitudinais são importantes por apontarem os diferentes elementos que foram priorizados ao longo do tempo (CARNEIRO; MASCARNHAS, 2018). Assim, temos como objetivo analisar o financiamento e gasto do ME de 2003 a 2018, tendo por base os Governos Lula, Dilma e Temer.

\section{METODOLOGIA}

Este estudo tem caráter quantitativo-qualitativo e se apoiou em levantamento documental. $\mathrm{O}$ recorte temporal se refere aos Governos Lula (2003-2010), Dilma (2011-2016) e Temer (20162018), ou seja, analisaremos o financiamento e gasto do ME de 2003 a 2018.

A coleta de dados foi realizada nas leis que dispõem sobre o Plano Plurianual (PPA) de cada Governo (MINISTÉRIO DA ECONOMIA, 2019) e o conjunto de dados da execução orçamentária presentes no SIGA Brasil (SENADO FEDERAL, 2019). Além disso, nos utilizamos do Portal da Legislação (BRASIL, 2019) para coleta das diferentes legislações que dão base ao financiamento e gasto do ME.

A análise dos dados foi realizada a partir da proposta metodológica desenvolvida por Carneiro e Mascarenhas (2018), em que apresentam que devem ser analisados três indicadores sobre o financiamento e gasto com esporte, neste caso esses foram adaptados para analisar o orçamento do ME: a) fontes de financiamento - visa compreender a origem dos recursos, sendo necessário analisar as legislações vigentes e os diferentes tributos que compuseram o orçamento do $\mathrm{ME}$; b) magnitude do gasto - se relaciona ao montante gasto em cada ano, tendo uma análise longitudinal, demonstrando a evolução da execução orçamentária, também apontam que se deve comparar em proporção a outros elementos, como o total do Orçamento Fiscal e da Seguridade Social (OFSS); e c) direção do gasto - está articulado ao direcionamento dos recursos, estabelecendo aquilo que foi priorizado ao longo tempo.

Os dados financeiros utilizados foram deflacionados pelo Índice Geral de Preços Disponibilidade Interna (IGP-DI), calculado pela Fundação Getúlio Vargas, a preços de dezembro de 2018, haja vista a necessidade de atualizar os valores para comparações longitudinais, 
eliminando os efeitos da inflação e da desvalorização da moeda. Para realizar este processo foi utilizada a ferramenta Calculadora Cidadã, disponibilizada pelo Banco Central do Brasil (2019).

A seguir serão apresentados e discutidos os dados do estudo a partir de três subseções, as fontes de financiamento, a magnitude do gasto e o direcionamento do gasto orçamentário do ME.

\section{O FINANCIAMENTO DO MINISTÉRIO DO ESPORTE}

O ME para concretização das suas ações contou com recursos orçamentários, de acordo com Salvador (2012b) esta fonte é a expressão mais visível do fundo público. Esta visão é ratificada por Carneiro (2018) no âmbito do esporte, pois ao analisar todos os recursos para o esporte de 2004 a 2015 apontou que o orçamento é a fonte de financiamento com maior volume de recursos, além de ser mais transparente e ter maior facilidade de acesso aos dados. Ademais, é o orçamento público “[...] que garante concretude à ação planejada do Estado e espelha as prioridades das políticas públicas que serão priorizadas pelo governo.” (SALVADOR, 2012a, p. 124).

Destarte, ter a partir de 2003 um ministério responsável exclusivamente pelo esporte foi importante para ampliação das políticas esportiva, como também para ter maior peso na disputa pelos recursos orçamentários, uma vez que a definição do orçamento federal é envolta por correlações de forças sociais e interesses para definir o que será priorizado no financiamento e gasto (SALVADOR, 2012b).

A execução orçamentária no Estado brasileiro se dá pela interação entre os poderes Legislativo e Executivo. A elaboração é realizada pelo Poder Executivo, que define o direcionamento do orçamento a partir dos programas de governo. O Poder Legislativo tem a obrigação de avaliar o orçamento, podendo aprová-lo, rejeitá-lo ou modificá-lo. Contudo, este processo se desenvolve permeado de influências das classes e frações de classe presentes no Estado (ATHAYDE; MASCARENHAS; SALVADOR, 2015).

Para identificação da execução orçamentária do ME nos utilizamos da classificação funcional-programática vigente, conforme Portaria do Ministério do Orçamento e Gestão n. 42/1999 - as bases desta portaria são a Lei n. 4.320/1964 e a Lei n. 9.649/1998 (alterada pela Medida Provisória n. 2.216-37/2001). Tal legislação prevê a função "Desporto e Lazer” como a rubrica que agrega o esporte e o lazer, bem como suas subfunções: "Desporto de Rendimento", "Desporto Comunitário" e "Lazer". Todos os recursos da função "Desporte e Lazer" de acordo com a classificação institucional foram executados pelo ME. A função "Desporto e Lazer" pode alocar recursos em outras subfunções, assim como outras funções podem alocar recursos nas três 
subfunções supracitadas, Carneiro (2018) e Mascarenhas (2016) identificaram que isso ocorreu ao longo dos Governos Lula e Dilma, contudo, aqui nosso foco será apenas o que foi gasto pelo ME, isto é, a partir da função "Desporto e Lazer”.

Os recursos orçamentários para o $\mathrm{ME}$ foram fruto de recursos ordinários, contribuições sobre concursos prognósticos e loterias e outros recursos orçamentários todos direcionados para a função "Desporto e Lazer" (CARNEIRO, 2018). Na Tabela 1 apresentamos as diferentes fontes de financiamento do ME.

Tabela 1 - Fontes de financiamento do ME - série 2003-2018

\begin{tabular}{|cccccc}
\hline Ano & $\begin{array}{c}\text { Recursos } \\
\text { ordinários }\end{array}$ & $\begin{array}{c}\text { Contribuições } \\
\text { sobre } \\
\text { concursos de } \\
\text { prognósticos }\end{array}$ & $\begin{array}{c}\text { Outras } \\
\text { contribuições } \\
\text { sociais }\end{array}$ & $\begin{array}{c}\text { Contribuição } \\
\text { Social sobres } \\
\text { Lucro Líquido } \\
\text { (CSLL) }\end{array}$ & $\begin{array}{c}\text { Remuneração } \\
\text { das } \\
\text { disponibilidad } \\
\text { es do Tesouro } \\
\text { Nacional }\end{array}$ \\
\hline 2003 & 212,66 & 37,37 & 0,00 & 0,00 & 0,00 \\
\hline 2004 & 423,01 & 159,12 & 0,14 & 0,00 & 0,00 \\
\hline 2005 & 786,63 & 105,91 & 0,00 & 0,00 & 0,00 \\
\hline 2006 & $1.269,54$ & 232,76 & 0,00 & 0,00 & 0,00 \\
\hline 2007 & $2.424,69$ & 277,55 & 0,00 & 0,00 & 0,00 \\
\hline 2008 & $1.456,21$ & 198,85 & 0,00 & 0,45 & 0,00 \\
\hline 2009 & $1.564,74$ & 152,66 & 0,00 & 0,00 & 0,00 \\
\hline 2010 & $1.533,94$ & 101,92 & 0,00 & 0,00 & 0,00 \\
\hline 2011 & $1.463,03$ & 245,79 & 0,00 & 0,00 & 14,78 \\
\hline 2012 & 445,54 & 80,44 & 0,00 & 0,00 & 0,00 \\
\hline 2013 & 451,17 & 77,57 & 0,00 & 0,00 & 0,00 \\
\hline 2014 & $1.002,52$ & 87,30 & 0,00 & 0,00 & 0,00 \\
\hline 2015 & 635,25 & 132,19 & 0,00 & 0,00 & 0,46 \\
\hline 2016 & 460,17 & 58,70 & 0,00 & 0,00 & 0,00 \\
\hline 2017 & 274,98 & 65,01 & 0,00 & 0,00 & 0,81 \\
\hline 2018 & 182,23 & 110,20 & 0,00 & 0,00 & 0,83 \\
\hline Total & $14.586,31$ & $2.123,34$ & 0,14 & 0,45 & 16,88 \\
\hline
\end{tabular}

Fonte: SIGA Brasil (Elaboração própria).

Obs.: 1. Valores liquidados; 2. Valores deflacionados pelo IGP-DI a preços de dezembro de $2018 \mathrm{em}$ R\$ milhões.

Os recursos ordinários são provenientes de impostos federais, especificamente, o Imposto de Renda (IR) e o Imposto sobre Produtos Industrializados (IPI), além dos recursos desvinculados das Contribuições Sociais (SALVADOR, 2012a). Esses recursos são discricionários, isto é, podem, ou não, serem direcionados para determinada função ou órgão.

Como pode ser visto na Tabela 1, a maioria dos recursos recebidos pelo ME de 2003 a 2018 foram provenientes de recursos ordinários, ou seja, 87,20\%. Contudo, por ser um recurso discricionário há falta de regularidade, facilmente observada na discrepância entre o ano com mais 
recursos desta fonte (2007) e o ano com menos (2018). Quando comparamos em relação aos períodos de Governo, o de Lula (2003 a 2010) foi o que teve maior média de recursos ordinários para o ME (R \$ 1,21 bilhões), a média do Governo Dilma (2011 a 2015) foi de R \$ 799,50 milhões e do Governo Temer (2017 a 2018) ${ }^{1}$ foi de R\$228,60 milhões. Observa-se, portanto, uma atuação mais contundente do Governo Lula no direcionamento de recursos ordinários ao ME, elemento que foi sendo reduzido ao longo dos Governos que o sucederam. É importante situar que esse comportamento acontece em todos os setores e que os governos foram permeados por contextos políticos e sobretudo econômicos distintos.

Em relação às contribuições sobre concursos prognósticos e loterias da função "Desporto e Lazer" a Lei n. 9.615/1998 (Lei Pelé) estabelecia que eram recursos do ME: a) receitas de concursos prognóstico previstos em lei; b) 4,5\% sobre cada bilhete de concurso prognóstico - deste percentual, 1/3 deve ser repassado às Secretarias de Esporte dos Estados e do Distrito Federal; c) $10 \%$ da loteria esportiva; d) prêmios de concursos prognóstico da loteria esportivo federal não reclamados; e, e) $10 \%$ do montante arrecadado Loteria Instantânea Exclusiva (LOTEX). É importante situar que no Governo Lula foi criada a Lei n. 11.345/2006 (Timemania), um concurso de prognóstico destinado aos clubes de futebol, em que 3\% da arrecadação ficaria com o ME. Já no Governo Dilma foi criada a Lei n. 13.155/2015 que instituiu a LOTEX, também voltada aos clubes de futebol.

De acordo com Matias e Mascarenhas (2017), a Timemania e a LOTEX foram uma das formas de atuação dos Governos Lula e Dilma para criar fontes de financiamento aos clubes de futebol endividados, juntamente com a criação de incentivos fiscais e alongamento de dívidas. De acordo com Carneiro (2018), houve uma atuação contundente dos Governos Lula e Dilma na criação de novas fontes de recursos para o setor esportivo - a Lei de Incentivo ao Esporte, novas loterias e concursos prognósticos e desonerações tributárias para os Megaeventos esportivos -, além de fortalecer as existentes, como o patrocínio esportivos das estatais.

O Governo Temer, por outro lado, buscando fortalecer os recursos para o Fundo Nacional de Segurança Pública instituiu a Medida Provisória (MP) n. 841/2018, que revogou em 11 de junho de 2018 todos os recursos de concursos prognósticos e loterias que a Lei Pelé garantia ao ME. Após ampla mobilização do setor esportivo no sentido de reverter a referida MP, depois de 50 dias foi editada a MP n. 846/2018 que depois foi convertida na Lei n. 13.756/2018. Se em um primeiro momento o ME correu o risco de ficar sem recursos de loterias e concursos prognósticos, posteriormente conseguiu garantir apenas parte dos recursos.

\footnotetext{
${ }^{1}$ Os Governo Dilma e o Governo Temer abarcam parcialmente o ano de 2016, por isso excluímos dos cálculos de média
} de ambos. Nas citações posteriores sobre os Governos Lula, Dilma e Temer serão utilizados estes períodos supracitados. 
Como pode ser visto na Tabela 1, dos recursos recebidos pelo ME de 2003 a 2018, 12,70\% foram fruto de loterias e concursos prognósticos. O ano com mais recursos desta fonte (2007) é mais de sete vezes maior que o ano de menor recurso (2003). Também nesta fonte é possível perceber grande oscilação dos valores, embora ela seja uma fonte de recurso que tem vinculação, isto é, os percentuais estabelecidos nas referidas leis devem ser obrigatoriamente direcionados ao ME. O Governo Lula foi o que teve uma média anual maior de recursos de loterias e concursos prognósticos ( $\mathrm{R} \$ 1,27$ bilhões), o Governo Dilma teve $\mathrm{R} \$ 623,30$ milhões de média e o Governo Temer teve R\$175,21 milhões.

De acordo com Amaral (2005), há volatilidade e imprevisibilidade da arrecadação das contribuições sobre concursos de prognóstico e loterias, isto se deve a questões como: introdução de novos produtos, mudanças na preferência do consumidor, variação nos esforços de marketing e acumulação em prêmios principais de concursos de prognósticos numéricos. Vimos que em 2006 (Timemania) e em 2015 (LOTEX) houve a introdução novos produtos de concursos prognósticos e loterias vinculado ao esporte, de 2006 em relação a 2005 os recursos de loterias mais que dobraram, já o ano de 2015 foi 66,04\% maior que 2014, contudo nos períodos posteriores teve grande oscilação destes recursos.

Além dos recursos ordinários e de loterias e concursos prognósticos o $\mathrm{ME}$ contou com recursos de outras fontes como: Outras contribuições sociais (R \$ 135,75 mil), Contribuição Social sobres Lucro Líquido (R $\$ 451,75$ mil) e Remuneração das disponibilidades do Tesouro Nacional (R\$ 16,88 milhões), montante que representou apenas $0,10 \%$ do orçamento do ME de 2003 a 2018.

\section{MAGNITUDE DO GASTO DO MINISTÉRIO DO ESPORTE}

O dimensionamento do gasto orçamentário, “[...] permite compreender e mensurar a importância dada a cada política pública no contexto histórico da conjuntura econômica, social e política vivenciada no país." (SALVADOR, 2012b, p. 8). Neste sentido, analisar a magnitude do gasto do ME é realizar o processo de compreensão desta pasta no contexto das disputas dentro do orçamento federal.

Inicialmente é importante apontar o processo de execução orçamentária do ME, isto é, os valores que foram planejados serem gastos e aqueles que foram efetivamente gastos (vide Tabela 2). A primeira fase é a Dotação Inicial que representa o valor inicial presente na Lei Orçamentária Anual (LOA), ou seja, o valor programado para ser gasto com cada política em cada ano; já o Autorizado é a Dotação Inicial acrescida e/ou deduzida dos créditos adicionais e/ou bloqueios. 
Como pode ser visto na Tabela 2, em 14 anos dos 16 anos analisados houve créditos adicionais, apenas em 2016 e 2017 que o Autorizado foi menor que a Dotação Inicial. No total, os valores Autorizados foram 20,92\% maior que a Dotação Inicial. Chama atenção que em 2007 o Autorizado foi $41,41 \%$ maior que a Dotação Inicial, tendo sido fruto da necessidade de o Governo Federal honrar com os compromissos com a realização do Jogos Pan Rio 2007, em 2010 (26,98\%) e 2012 $(28,30 \%)$ também registram quantitativo significativo de créditos adicionais ao ME.

Tabela 2 - Execução orçamentária do ME - série 2003 a 2018

\begin{tabular}{ccccccc}
\hline Ano & $\begin{array}{c}\text { Dotação } \\
\text { Inicial }\end{array}$ & $\begin{array}{c}\text { Autorizad } \\
\mathbf{0}\end{array}$ & $\begin{array}{c}\text { Empenhad } \\
\mathbf{o}\end{array}$ & Liquidado & $\begin{array}{c}\text { Liquidado/ } \\
\text { Autorizad } \\
\text { o (\%) }\end{array}$ & $\begin{array}{c}\text { Liquidado/ } \\
\text { OFSS (\%) }\end{array}$ \\
\hline 2003 & 860,81 & 865,19 & 384,83 & 250,03 & 28,90 & 0,012 \\
2004 & 767,77 & 823,17 & 582,27 & 582,27 & 70,73 & 0,030 \\
2005 & $1.331,93$ & $1.445,36$ & 892,54 & 892,54 & 61,75 & 0,038 \\
2006 & $1.804,16$ & $2.075,04$ & $1.502,30$ & $1.502,30$ & 72,40 & 0,062 \\
2007 & $1.763,21$ & $3.009,41$ & $2.702,35$ & $2.702,25$ & 89,79 & 0,116 \\
\hline 2008 & $1.956,24$ & $2.392,37$ & $1.655,51$ & $1.655,51$ & 69,20 & 0,077 \\
2009 & $2.443,83$ & $2.559,74$ & $1.717,40$ & $1.717,40$ & 67,09 & 0,069 \\
2010 & $2.394,77$ & $3.279,50$ & $1.635,86$ & $1.635,86$ & 49,88 & 0,069 \\
2011 & $3.595,86$ & $4.060,70$ & $1.723,60$ & $1.723,60$ & 42,45 & 0,069 \\
2012 & $3.585,80$ & $5.001,09$ & $1.753,16$ & 525,98 & 10,52 & 0,022 \\
2013 & $4.428,86$ & $5.451,90$ & $3.062,71$ & 528,74 & 9,70 & 0,022 \\
\hline 2014 & $2.842,54$ & $4.208,12$ & $3.083,04$ & $1.089,82$ & 25,90 & 0,039 \\
\hline 2015 & $3.734,60$ & $3.931,28$ & $2.347,71$ & 767,90 & 19,53 & 0,029 \\
\hline 2016 & $1.811,81$ & $1.804,74$ & $1.519,30$ & 518,87 & 28,75 & 0,019 \\
\hline 2017 & 1527,83 & $1.629,22$ & 1396,81 & 340,79 & 20,92 & 0,013 \\
\hline 2018 & $1.276,48$ & $1.306,46$ & $1.239,82$ & 293,27 & 22,45 & 0,011 \\
\hline Total & $36.126,51$ & $43.843,29$ & $27.199,20$ & $16.727,12$ & 38,15 & 0,039 \\
\hline
\end{tabular}

Obs.: Valores deflacionados pelo IGP-DI a preços de dezembro de 2018 em R\$ milhões.

O Empenho constitui a primeira fase da despesa orçamentária, e é registrado no momento em que o bem ou serviço é contratado, quando a autoridade competente cria para o Estado a obrigação de pagamento pendente, expede-se a garantia ao credor do ente público que há crédito suficiente para liquidação do compromisso assumido (SENADO FEDERAL, 2018). No total dos 16 anos em análise apenas 60,18\% dos recursos Autorizados foram Empenhados, gerando um contingenciamento de $\mathrm{R} \$ 17,39$ bilhões do ME no período. O contingenciamento se refere ao processo em que o poder executivo retarda ou deixa de executar parte da programação da despesa prevista no Autorizado, isso busca atender as metas fiscais, procurando fazer com que o Estado não gaste mais do que foi arrecadado, além de garantir que parte dos recursos sejam encaminhados para 
gerar superávit primário - honrar os compromissos do Estado com o capital portador de juros (ATHAYDE, 2014; CARNEIRO, 2018).

O Liquidado é a segunda etapa da despesa orçamentária, que se dá quando a unidade executora recebe o objeto do Empenho, confirmando que o bem foi entregue ou o serviço foi executado. A partir da Tabela 2 identificamos que apenas 38,15\% dos recursos Autorizados foram Liquidados no período, enquanto apenas 61,50\% dos recursos Empenhados foram Liquidados. Dessarte, houve contingenciamento de recursos do $\mathrm{ME}$, não havendo a Liquidação de parte dos valores Autorizados e Empenhados.

Ao comparar o Liquidado com o Autorizado em relação aos períodos de governos, há grandes diferenças, no Governo Lula a execução média foi de $63,72 \%$, no Governo Dilma foi de $21,62 \%$ e no Governo Temer foi de 13,6\%. Assim, cada vez mais os recursos do ME foram sendo contingenciados para atender interesses econômicos em detrimento da política esportiva (CARNEIRO, 2018).

Conforme pode ser observado na Tabela 2 ocorreu bastante variação nos recursos Liquidados pelo ME. A média anual de gasto pelo ME no Governo Lula foi de R\$ 1,38 bilhões, no Governo Dilma foi de R\$ R\$ 927,2 milhões e no Governo Temer foi de R\$ 181,07 milhões. Depreende-se, portanto, que o maior contingenciamento de recursos do ME durante os Governos Dilma e Temer em relação ao Governo Lula afetaram diretamente os gastos realizados pela pasta. Enquanto em 2007 (Governo Lula) o ME gastou R\$ 2,70 bilhões - fruto do gasto com a realização dos Jogos Pan Rio 2007 -, em 2017 (Governo Temer) esse valor foi de apenas R\$ 68,82 milhões, isto é, aquele foi mais de 38 vezes maior.

Ainda na Tabela 2, apresentamos os valores gastos pelo ME em relação ao gasto do OFSS. Ao longo dos 16 anos analisados a média de gasto do ME em relação ao OFSS foi de 0,038\%. Os valores apresentados na Tabela 2 estão longe daquilo que foi estabelecido como meta pelo Plano Decenal de Esporte e Lazer e nas I e II Conferências Nacionais do Esporte, respectivamente, 2\% e $1 \%$ do orçamento da União para o esporte. O ME foi uma das pastas ministeriais com menos recursos ao longo dos diferentes governos (CARNEIRO, 2018), já a pequena participação do gasto do ME em relação ao OFSS tem sido algo bastante presente, conforme constatado por outros estudos (ATHAYDE, 2014; MASCARENHAS, 2016; CARNEIRO, 2018; CARNEIRO et al., 2019). Na disputa pelos recursos orçamentários, o ME teve uma participação irrisória.

\section{DIRECIONAMENTO DO GASTO DO MINISTÉRIO DO ESPORTE}


Para analisar o direcionamento do gasto com esporte nos pautaremos nos PPAs 2000-2003, 2004-2007, 2008-2011, 2012-2015 e 2016-2019, vigentes ao longo dos governos que abarcam o objeto de pesquisa. O PPA é uma peça legislativa constituinte do ciclo orçamentário brasileiro, consagrados pela Constituição Federal de 1988, no art. 165, ele estabelece o conjunto das políticas públicas do governo para um período de 4 anos, havendo a previsão de metas, sendo a partir do PPA que são elaboradas a Lei de Diretrizes Orçamentárias (LDO) e a Lei Orçamentária Anual (LOA), isto é, as ações consignadas no orçamento federal partem do PPA.

Dessarte, o PPA é a peça técnica e política que baliza todo o governo de um mandato presidencial, tendo impacto direto sobre o financiamento das políticas públicas, dentre elas o esporte. Enquanto nos PPAs 2000-2003, 2004-2007 e 2008-2011 existia uma organização por programas finalísticos, havendo aqueles vinculados ao esporte, nos PPAs 2012-2015 e 2016-2019 a organização se deu por programas temáticas - no primeiro foi intitulado "Esporte e Grandes Eventos" e no segundo "Esporte, Cidadania e Desenvolvimento" - e programas de gestão e manutenção específicos para o ME.

A nova organização do PPA 2012-2015, a partir de programas temáticos e programas de gestão, sofreu inúmeras críticas, uma vez que, ao agrupar os programas, causou dificuldade em monitorar as políticas públicas, ocasionando generalização e esvaziamento dessas ações como categoria de programação de despesa (CABRAL, 2012) - este mesmo modelo de construção do PPA foi utilizado no PPA 2016-2019. No âmbito do esporte, isto impactou mais diretamente as políticas de Esporte, Educação, Lazer e Inclusão Social (EELIS), pois programas finalísticos dos PPAs 2004-2007 e 2008-2011 ligados aos povos/cultura indígena, à inclusão social, ao Esporte e Lazer da Cidade (PELC) e ao Programa Segundo Tempo (PST), passaram a ser apenas um objetivo do programa temático de esporte nos PPA 2012-2015 e 2016-2019.

Assim, estudos que trabalharam com a discussão de programas finalísticos como o PST (ATHAYDE, 2011; MATIAS, 2012), o PELC (TEIXEIRA et al., 2014) ou ambos os programas (ATHAYDE, 2014; ATHAYDE; SALVADOR; MASCARENHAS, 2015; CASTRO, 2016) teriam dificuldades em realizar a continuidade destes estudos no que se refere ao gasto, pois não há discriminação do gasto por programas finalístico no SIGA Brasil no período de 2012 a 2018.

Tendo por base os 5 PPAs do período que vai de 2003 a 2018 sistematizamos a presença de categorias de direcionamento de gasto do ME: EELIS, Esporte de Alto Rendimento (EAR) Megaeventos e Gestão. Todavia, há uma quinta categoria, Infraestrutura, pois no momento da consolidação dos dados, notamos que um percentual significativo de recursos ME estava vinculado à construção, ampliação ou modernização de equipamentos esportivos. Estas 5 categorias de gasto 
público federal com o esporte têm sido utilizadas por diferentes estudos (MASCARENHAS, 2016; TEIXEIRA, 2016; PEREIRA, 2017; CARNEIRO et al., 2019). Na Tabela 3 apresentamos o direcionamento do gasto com esporte, tendo por base as categorias supracitadas.

Tabela 3 - Direcionamento do gasto do ME por categoria - série 2003-2018

\begin{tabular}{cccccc}
\hline Ano & EAR & EELIS & Gestão & $\begin{array}{c}\text { Infraestrutur } \\
\text { a }\end{array}$ & Megaeventos \\
\hline 2003 & 12,54 & 51,81 & 2,97 & 182,71 & 0,00 \\
2004 & 11,64 & 122,28 & 57,45 & 299,13 & 91,76 \\
2005 & 57,88 & 247,03 & 65,10 & 510,41 & 12,11 \\
2006 & 38,09 & 268,73 & 106,35 & 581,85 & 507,29 \\
2007 & 110,20 & 313,05 & 137,46 & 740,30 & $1.401,25$ \\
2008 & 57,90 & 280,11 & 133,49 & $1.077,50$ & 106,50 \\
2009 & 81,88 & 304,64 & 146,24 & $1.184,63$ & 0,00 \\
2010 & 65,83 & 336,31 & 155,63 & 805,93 & 272,16 \\
2011 & 100,19 & 318,98 & 183,99 & 805,64 & 314,81 \\
2012 & 119,12 & 38,41 & 146,55 & 4,18 & 217,72 \\
2013 & 173,89 & 59,97 & 129,90 & 19,04 & 145,95 \\
2014 & 175,70 & 112,45 & 154,45 & 0,51 & 646,71 \\
2015 & 120,27 & 106,73 & 146,39 & 9,82 & 384,69 \\
2016 & 58,04 & 43,60 & 128,43 & 40,44 & 248,35 \\
2017 & 53,57 & 35,75 & 131,96 & 119,51 & 0,00 \\
\hline 2018 & 33,50 & 47,51 & 126,09 & 86,17 & 0,00 \\
\hline Total & $1.270,22$ & $2.687,36$ & $1.952,46$ & $6.467,78$ & $4.349,30$ \\
\hline
\end{tabular}

Fonte: SIGA Brasil (Elaboração própria).

Obs.: Valores deflacionados pelo IGP-DI a preços de dezembro de 2018 em R \$ milhões.

O EAR é a categoria que está relacionada aos gastos vinculados à preparação e participação de atletas em competições de alto rendimento, estes gastos foram realizados pela SNEAR secretaria do ME que existiu de 2003 a 2018. Já o EELIS se refere aos gastos do ME com políticas para o acesso ao esporte e lazer realizado inicialmente (2003 a 2011) pela SNEED e SNDEL e posteriormente (2011-2018) pela SNEELIS - parte do nome desta secretaria dá título à categoria. Os gastos com EAR e EELIS estão relacionados a vivência e prática esportiva. Vale destacar que na Constituição Federal de 1988 foi estabelecida a priorização de gasto na manifestação educacional e em casos específicos, o esporte de rendimento. Se entendermos que EELIS corresponde à totalidade da manifestação educacional, podemos ver que no total do período houve mais gasto com EELIS (R\$ 2,68 bilhões) do que com EAR (R\$ 1,27 bilhão), tendo se cumprido o preceito constitucional. Contudo, cabe observar que em todo o Governo Lula a categoria EELIS foi maior que a EAR, 
enquanto no Governo Dilma e no Governo Temer isso aconteceu apenas em um ano, respectivamente, em 2011 e 2018.

Já no final do Governo Lula foi construído o Plano Decenal de Esporte e Lazer - fruto da III Conferência Nacional do Esporte - que influenciou diretamente a política esportiva do Governo Dilma, os reflexos disso são as alterações na estrutura organizacional do ME, o foco do PPA 20122015 no EAR e Megaeventos esportivos e alterações nas legislações esportivas (FLAUSINO, 2013; CARNEIRO, 2018). Buscando ampliar o quantitativo de recursos para o EAR, foi lançado pelo Governo Federal em setembro de 2012 o Plano Brasil Medalhas 2016, cujo objetivo era colocar o Brasil entre os dez primeiros países nos Jogos Olímpicos, e entre os cinco primeiros nos Jogos Paraolímpicos, em 2016, para isso, o ME e as empresas estatais deveriam alocar R\$ 1 bilhão adicional no esporte. Como pode ser visto, houve uma atuação contundente do Governo Dilma para que o ME alocasse mais recurso no EAR, haja vista o interesse que o Brasil obtivesse bons resultados nos Jogos Rio 2016. Assim, o Governo Dilma foi o que teve maior média anual de gasto com EAR (R\$ 137,83 milhões), a média anual do Governo Lula foi de R\$ 54,95 milhões e do Governo Temer foi de R \$ 43,53 milhões.

O EAR teve R\$ 1,27 bilhões de gastos pela ME ao longo dos 16 anos. Deste valor, R\$ 842,38 milhões foram para a ação de "Concessão de Bolsa Atleta" ao longo de 2005 a 2018, se configurando o Programa Bolsa Atleta como o foco de gasto da SNEAR, sendo a primeira política federal que beneficiou financeiramente os atletas diretamente (CORRÊA et al., 2014), além de ter possibilitado uma melhor participação dos atletas nos Jogos Olímpicos (TEIXEIRA et al., 2017), esta foi a principal política de EAR do ME. A segunda ação de EAR com mais gasto (R\$163,58 milhões) foi a de "Preparação de atletas e capacitação de recursos humanos para o esporte de alto rendimento", esta foi a única ação de EAR que se fez presente de 2003 a 2018. A terceira ação com mais gasto (R\$ 69,62 milhões) foi a de "Participação de delegação brasileira em competições internacionais de alto rendimento". Além dessas ações, registram-se outras, como: promoção de eventos de EAR, gestão da Rede Nacional de Treinamento, funcionamentos de núcleos de EAR, fomente ao esporte de base, realização da política antidoping, etc.

Ao longo do período foram gastos com EELIS cerca de R\$ 2,69 bilhões. A maioria deste recurso (R\$ 1,63 bilhão) foi gasto com a ação de "Funcionamento de núcleos de esporte educacional", materializando o PST de 2003 a 2011, assim, esse programa foi foco da SNEED e a principal política de esporte educacional. A segunda ação com mais recursos ( $\mathrm{R} \$ 311,99$ milhões) foi a de "Desenvolvimento de atividades e apoio a projetos de esporte, educação, lazer, inclusão social e legado social" realizada ao longo de 2012 e 2018, abarcando em grande medida a realização do PST e do PELC, que foram concretizados pela SNEELIS a partir de 2012. A terceira 
ação com mais recurso ( $\mathrm{R}$ \$ 237,47 milhões) foi a de "Inserção social pela produção de material esportivo" concretizada de 2003 a 2011. A quarta ação com mais recurso (R \$ 233,48 milhões) foi a de "Funcionamento de núcleos de esporte recreativo e de lazer", ou seja, o funcionamento dos núcleos do PELC de 2003 a 2011. Estas quatro ações expressam em grande parte aquilo que foi concretizado pelo ME em relação a categoria EELIS, pois apontam os gastos para os dois principais programas de acesso ao esporte e lazer do ME - o PST e o PELC.

Em um primeiro momento, o Governo Lula focou sua atuação no desenvolvimento dos programas sociais esportivos, sobretudo, PST e PELC (CARNEIRO, 2018). Mas, a partir de 2007 no segundo mandato de Lula - com a realização dos Jogos Pan Rio 2007, houve uma inflexão para realização dos Megaeventos esportivos (ATHAYDE, 2011), que passaram a ser o princípio organizador da agenda política de esporte e lazer no Brasil (MASCARENHAS et al., 2012), elemento que se fez presente no final do Governo Lula e Dilma. O gasto com Megaeventos esportivos foi o segundo maior com R\$ 4,35 bilhões, estes financiaram três Megaeventos: Jogos Pan Rio 2007, Copa do Mundo FIFA 2014 e Jogos Rio 2016.

Os Jogos Pan Rio 2007 tiveram gasto total de R\$ 2 bilhões ao longo de 2004 a 2007 69,48\% deste recurso foi gasto em 2007 ano de realização do evento -, deste valor, R \$ 1,48 bilhão foi para implantação de infraestrutura e R \$ 518,87 milhões foram para a realização dos Jogos. A Copa do Mundo FIFA 2014 gastou R\$ 183,63 milhões ao longo de 2010 a 2014, destes, R\$ 144,98 milhões foram para "Apoio a realização da Copa do Mundo FIFA 2014” e R\$ 38,65 milhões foram para "Implantação de controle de acesso e monitoramento nos estádios de futebol para segurança do torcedor”. Os Jogos Rio 2016 gastaram R\$ 2,16 bilhões, em 2007 e 2008 foram gastos R\$ 116,22 na captação deste Megaevento, em 2010 e 2013 foram gastos R\$ 66,12 milhões com a "Participação da União no capital da Empresa Brasileira de Legado Esportivo s.a.”, em 2011 e 2012 houve gasto de R\$ 174,06 milhões para constituição da Autoridade Pública Olímpica e de 2010 a 2016 foram gastos R\$ 1,26 bilhão na implantação de infraestrutura e R\$ 550,36 milhões na preparação e organização. Os três Megaeventos esportivos gastaram R\$ 2,84 bilhões com infraestrutura esportiva para que fossem realizados, isto representa $65,41 \%$ de tudo que foi gasto com eles.

O maior gasto do ME foi com Infraestrutura esportiva, foram R \$ 6,47 bilhões. Deste gasto, R\$ 6,33 bilhões foram com Infraestrutura de EELIS, R\$ 119,98 milhões com Infraestrutura de EAR e R\$ 19,13 milhões foram gastos na “Gestão e Manutenção do Legado Olímpico e Paraolímpico sob responsabilidade da Autoridade de Governança do Legado Olímpico" - este gasto realizado em 2018. Do gasto com Infraestrutura de EELIS, de 2003 a 2011 houve R\$ 5,71 bilhões gasto com a “Implantação e modernização de núcleos de esporte recreativo e de lazer" e R\$ 396,96 milhões gasto com a "Implantação de infraestrutura para o desenvolvimento do esporte educacional", a 
partir de 2012 até 2018 os gastos com estas duas ações foram agregadas na ação de "Implantação e modernização de infraestrutura para esporte educacional, recreativo e de lazer" com R\$30,08 milhões. Ainda como Infraestrutura de EELIS identifica-se R\$ 905,53 mil com a "Implantação de Centros de Desenvolvimento do Esporte Recreativo e de Lazer - Rede CEDES” em 2004 e 2005. Enquanto gasto com EAR houve R\$ 60,33 milhões para "Implantação e modernização de infraestrutura para o esporte de alto rendimento" ação que se deu em diferentes anos (2003, 2008, 2009, 2013 e de 2015 a 2018) e R\$ 59,65 milhões para "Implantação e modernização de Centros Científicos e Tecnológicos Para o Esporte" de 2003 a 2011.

A média de gasto anual com Infraestrutura esportiva de cada Governo é bem diferente, sobretudo comparando o gasto do Governo Lula (R\$ 672,80 milhões) com os Governos Dilma (R\$ 167,84 milhões) - o gasto em 2011 representou 96\% de todo o gasto com Infraestrutura esportiva do Governo Dilma - e Temer (R\$ 102,84 milhões). Para Mascarenhas (2016), o grande investimento do Governo Lula em Infraestrutura - inclusive de esporte - por meio de obras públicas foi uma política anticíclica para lidar com a crise financeira global de 2007-2008, além disso expressa um papel interventor do Estado no âmbito esportivo, colocando o esporte a serviço do desenvolvimento econômico, mobilizando diversos interesses do Poder Executivo e Legislativo (CARNEIRO, 2018). Ademais foi uma das formas de colocar em prática a perspectiva (neo)desenvolvimentista presente no segundo mandato do Governo Lula e início do Governo Dilma.

O grande gasto realizado para Infraestrutura esportiva só foi possível devido aos recursos de emendas parlamentares, de acordo com Carneiro (2018), de 2004 a 2015, 95,58\% dos recursos de Infraestrutura esportiva do ME foi fruto deste tipo de recurso. Para Teixeira (2016), as emendas parlamentares são bastante utilizadas para a área de construção, ampliação e modernização de espaços esportivos, porém seriam uma forma de limitar e pouco acrescentariam às políticas públicas esportivas. Essa seria uma prática clientelista que “[...] corrobora para a pulverização dos recursos públicos, ou seja, para a distribuição dos gastos com o esporte por inúmeras obras, através de parcelas muitas vezes insuficiente para a conclusão de projetos” (MASCARENHAS, 2016, p. 975). Este tipo de recurso articularia demandas locais com interesses econômicos e políticos de parlamentares, além de interesses econômicos de empreiteiras (CARNEIRO, 2018).

O gasto com Gestão do $\mathrm{ME}$ (R\$ 1,95 bilhão) se refere aos recursos para manutenção das atividades da pasta. A ação que mais teve recurso (R\$ 1,07 bilhão) foi a de "Administração da unidade", em seguida foi a de gasto com "Pessoal (pagamento e encargos sociais)" com R\$325,95 milhões e em terceiro foi a de "Publicidade" com R\$ 269,78 milhões. Complementarmente, ocorreram gastos com “Gestão de programas” (R\$ 165,93 milhões), “Avaliação de políticas 
públicas de esporte e lazer" (R\$ 55,76 milhões), “Capacitação de pessoal” (R\$ 17,36 milhões) etc. A média anual de gasto com Gestão no Governo Lula foi de R\$ 100,59 milhões, no Governo Dilma foi de R\$ 152,26 milhões e no Governo Temer foi de R\$129,03 milhões, contudo quando se olha percentualmente o gasto médio com a categoria Gestão em relação ao total de gasto é possível identificar um crescimento crescente, no Governo Lula foi 7,08\%, no Governo Dilma foi 19,27\% e no Governo Temer foi R\$ 40,86\%. A nível de comparação, Mascarenhas (2016) aponta que a média de gasto com Gestão da Secretaria Nacional de Esporte no Ministério do Esporte e Turismo do Governo Fernando Henrique Cardoso era de $1 \%$.

\section{CONSIDERAÇÕES FINAIS}

Tendo por base os períodos dos Governos presidenciais de Lula, Dilma e Temer - nos quais existia o ME -, foi possível analisar o financiamento e gasto da referida pasta. Ficou claro que a maior parte dos recursos do ME são discricionários, embora tenha sido de grande importância os recursos de concursos prognóstico e loterias. Além disso, quando se verifica a execução orçamentária do ME, evidencia-se sua pouca participação no OFSS, além da maior parte dos recursos Autorizados no período serem contingenciados, não havendo sua Liquidação, elemento que expressa os compromissos da União com o ajuste e superávit fiscal.

No direcionamento dos recursos do ME ficou claro que, embora no total a maior parte dos gastos tenho sido para Infraestrutura e Megaeventos esportivos, ao longo dos três governos as prioridades foram diferentes. No período do Governo Lula, quase metade dos recursos foram para Infraestrutura - a grande maioria foi para Infraestrutura de EELIS -, além disso, parte relevante foi para Megaeventos e EELIS. Já no Governo Dilma, a prioridade foi com a realização dos Megaeventos esportivos (Copa do Mundo FIFA 2014 e Jogos Rio 2016). No Governo Temer as categorias que mais tiveram gasto foram Gestão e Infraestrutura.

Se em um primeiro momento de existência do ME vieram em primeiro plano a garantia do acesso ao esporte por meio de políticas como o PST e o PELC, estes foram secundarizados em relação a outros compromissos assumidos pela pasta com a realização dos Megaeventos esportivos e o maior financiamento ao EAR. Os gastos com Infraestrutura e os Megaeventos esportivos estiveram vinculados a perspectiva (neo)desenvolvimentista presentes nos Governos Lula e Dilma, assim, o esporte esteve a serviços dos interesses econômicos e políticos dos referidos Governos.

O estudo priorizou uma análise longitudinal dos 16 anos de existência do ME. É importante que novos estudos busquem analisar sobre como a extinção o ME impactará seu financiamento e gasto, pois, o esporte mesmo com um Ministério específico teve recursos diminutos no contexto do 
OFSS. Agora, como Secretaria Especial, é provável que tenha menor influência sobre o orçamento da União. Se ainda não é possível dizer aquilo que a Secretaria Especial do Esporte será em termos de financiamento e gasto, é possível olhar para retrovisor e ver aquilo que o ME foi. Conforme apresentamos neste texto, seu foco não foi no desenvolvimento de políticas voltadas às práticas esportivas (EELIS e EAR), mas sim no atendimento a interesses econômicos e políticos (Infraestrutura e Megaeventos), que nem sempre estiveram articulados ao esporte como direito.

\section{REFERÊNCIAS}

ALMEIDA, Bárbara Schausteck de; MARCHI JÚNIOR, Wanderley. O financiamento dos programas federais de esporte e lazer no Brasil (2004 a 2008). Movimento, Porto Alegre, v. 16, n. 04, p. 73-92, out./dez. 2010.

AMARAL, José Ronaldo do. As loterias federais brasileiras: um estudo da arrecadação e de sua previsão. 2005. Dissertação (Mestrado em Economia do Setor Público) - Universidade de Brasília, Brasília, 2005.

ANDERSON, Perry. O Brasil de Lula. Novos Estudos, n. 91, p. 23-52, nov. 2011.

ATHAYDE, Pedro Fernando Avalone. O "lugar do social" na Política de Esporte do Governo Lula. SER Social, Brasília, v. 13, n. 28, p. 184-209, jan./jun. 2011.

ATHAYDE, Pedro Fernando Avalone. O ornitorrinco de chuteiras: determinantes econômicos da política de esporte e lazer do governo Lula e suas implicações sociais. 2014. Tese (Doutorado em Política Social) - Universidade de Brasília, Brasília, 2014.

ATHAYDE, Pedro Fernando Avalone; MASCARENHAS, Fernando; SALVADOR, Evilasio. Primeiras aproximações de uma análise do financiamento da política nacional de esporte e lazer no governo Lula. In: MATIAS, Wagner Barbosa; Athayde, Pedro Fernando Avalone; MASCARENHAS, Fernando (Orgs.). Política de esporte nos anos Lula e Dilma. Brasília: Thesaurus, 2015. p. 117-139.

BANCO CENTRAL DO BRASIL. Calculadora Cidadã. 2019. Disponível em: https://www3.bcb.gov.br/CALCIDADAO/publico/corrigirPorIndice.do?method=corrigirPorIndice. Acesso em: 10 abr. 2019.

BRASIL. 2003. Disponível em: http://www.planalto.gov.br/ccivil 03/decreto/2003/D4668.htm. Acesso em: 13 abr. 2019.

BRASIL. 2011. Disponível em: http://www.planalto.gov.br/ccivil 03/ Ato20112014/2011/Decreto/D7529.htm. Acesso em: 13 abr. 2019.

BRASIL. Portal da legislação. 2019. Disponível em: http://www4.planalto.gov.br/legislacao/. Aceso em: 10 mar. 2019. 
BOITO JÚNIOR, Armando. As bases políticas do neodesenvolvimentismo. Trabalho apresentado na edição de 2012 do Fórum Econômico da FGV/São Paulo. 2012a. Disponível em:

http://bibliotecadigital.fgv.br/dspace/bitstream/handle/10438/16866/Painel\%203\%20-

\%20Novo $\% 20$ Desenv $\% 20$ BR $\% 20-\% 20$ Boito $\% 20-\% 20$ Bases $\% 20$ Pol $\% 20$ Neodesenv $\% 20$ -

\%20PAPER.pdf? sequence $=1$. Acesso em: 21 jan. 2017

BOITO JÚNIOR, Armando. A burguesia brasileira no golpe do impeachment. Brasil de Fato, São Paulo, 6 jan. 2017. Disponível em: https://www.brasildefato.com.br/2017/01/06/a-burguesiabrasileira-no-golpe-do-impeachment/. Acesso em: 15 mai. 2019.

Cabral, Gilda. Chega de conversa fiada: Governo Dilma inviabiliza controle social das políticas públicas [internet]. Brasília: 2012 Out. 25. Disponível em:

http://www.inesc.org.br/biblioteca/publicacoes/artigos/chega-de-conversa-fiada. Acesso em: 15 mai. 2019.

CARNEIRO, Fernando Henrique Silva. O financiamento do esporte no Brasil: aspectos da atuação estatal nos governos Lula e Dilma. 2018. 385 f. Tese (Doutorado em Educação Física) Universidade de Brasília, Brasília, 2018.

CARNEIRO, Fernando Henrique Silva et al.. Orçamento do esporte no governo Dilma: a primazia dos interesses econômicos e o direito escanteado. RBCE, Brasília, 2019. No prelo.

CARNEIRO, Fernando Henrique Silva; MASCARENHAS, Fernando. O financiamento esportivo brasileiro: proposta de metodologia crítica de análise. E-legis, Brasília, v. 11, n. Especial Pesquisas e Políticas sobre Esporte II, p. 119-140, nov. 2018.

CASTRO, Suélen Barboza Eiras de. Políticas públicas para o esporte e lazer e o ciclo orçamentário brasileiro (2004-2011): prioridades e distributição de recursos durante os processos de elaboração e execução orçamentária. 2016. Tese. (Doutorado em Educação Física) - Universidade Federal do Paraná, Curitiba, 2016.

CASTRO, Suélen Barboza Eiras de; SCARPIN, Jorge Eduardo; SOUZA, Doralice Lange de. Financiamento público e esporte educacional: uma análise do processo orçamentário do programa "Segundo Tempo" (2004-2011). Motrivivência, Florianópolis, v. 29, n. 52, p. 136-156, set. 2017.

CORRÊA, Amanda Jorge et al.. Financiamento do esporte olímpico de verão brasileiro: mapeamento inicial do programa "Bolsa Atleta" (2005-2011). Pensar a Prática, Goiânia, v. 17, n. 4, out./dez. 2014.

COUTINHO, Carlos Nelson. A hegemonia da pequena política. In: OLIVEIRA, Francisco de; BRAGA, Ruy; RIZEK, Cibele. (Orgs.). Hegemonia às avessas. São Paulo: Boitempo, 2010. pp. 29-46.

FILGUEIRAS, Luiz. Notas para a análise de conjuntura. In: PINTO, Eduardo Costa; FIGUEIRAS, Luiz; GONÇALVES, Reinaldo. Governo Dilma, PT, esquerda e impeachment: Três interpretações da conjuntura econômica e política. UFRJ, Instituto de Economia. Texto para Discussão 015. Set. 2015. Disponível em: http://www.ie.ufrj.br/images/pesquisa/publicacoes/discussao/2015/TD IE 0152015 PINTO FIL GUEIRAS GONALVES.pdf. Acesso em: 15 dez. 2016. 
FIGUERÔA, Katiuscia Mello et al. Planejamento, ações e financiamento para o esporte em tempos de megaeventos. Motrivivência, v. 26, n. 42, p. 55-71, jun. 2014.

FLAUSINO, Michelle da Silva. Plano Decenal: as políticas públicas de esporte e lazer em jogo. 2013. Dissertação (Mestrado em Educação Física) - Universidade de Brasília, Brasília, 2013.

FRIGOTTO, Gaudêncio. Brasil e a política econômico-social: entre o medo e a esperança. In: Observatório Social de América Latina, Buenos Aires: CLACSO, ano V, n. 14, p. 95-105, mai./ago. 2004.

MASCARENHAS, Fernando. O orçamento do esporte: aspectos da atuação estatal de FHC a Dilma. ®. Bras. Educ. Fís. Esporte, São Paulo, v. 30, n. 4, p. 963-80, out./dez. 2016.

MASCARENHAS, Fernando. Et al.. O Bloco Olímpico: Estado, organização esportiva e mercado na configuração da agenda Rio 2016. Revista da ALESDE, Curitiba, v. 2, n. 2, p. 15-32, out. 2012.

MATIAS, Wagner Barbosa. A política esportiva do governo Lula: o Programa Segundo Tempo. Licere, Belo Horizonte, v. 16, n. 1, p. 1-23, mar. 2013.

MATIAS, Wagner; MASCARENHAS, Fernando. Caracterização histórica e a legislação sobre o futebol no Brasil. Licere, Belo Horizonte, v. 20, n. 4, dez/2017.

MINISTÉRIO DA ECONOMIA. Planos Plurianuais. 2019. Disponível em: http://www.planejamento.gov.br/assuntos/planeja/plano-plurianual. Acesso em: 13 mai. 2019.

MINISTÉRIO DO ESPORTE. Histórico. 2018. Disponível em: http://portal.esporte.gov.br/institucional/historico.jsp. Acesso em: 10 mar. 2019.

OLIVEIRA, Francisco de. Hegemonia às avessas. In: OLIVEIRA, Francisco de; BRAGA, Ruy; RIZEK, Cibele. (Orgs.). Hegemonia às avessas. São Paulo: Boitempo, 2010ª pp. 21-28. PEREIRA, Claudia Catarino. As empresas estatais e o financiamento do esporte nos governos Lula e Dilma. 2017. Dissertação (Mestrado em Educação Física) -Universidade de Brasília, Brasília, 2017.

PINTO, Eduardo Costa. Dilma: de "coração valente" à "presidenta acuada". In: PINTO, Eduardo Costa; FIGUEIRAS, Luiz; GONÇALVES, Reinaldo. Governo Dilma, PT, esquerda e impeachment: Três interpretações da conjuntura econômica e política. UFRJ, Instituto de Economia. Texto para Discussão 015. Set. 2015. Disponível em: http://www.ie.ufrj.br/images/pesquisa/publicacoes/discussao/2015/TD IE 0152015 PINTO FIL GUEIRAS GONALVES.pdf. Acesso em: 15 dez. 2016.

PINTO, Eduardo Costa et al.. A economia política dos governos Dilma: acumulação, bloco no poder e crise. UFRJ, Instituto de Economia. Texto para Discussão 004, 2016. Disponível em: http://www.ie.ufrj.br/images/pesquisa/publicacoes/discussao/2016/TD IE 0042016 COSTA PIN TO et al.pdf. Acesso em: 01 jan. 2017.

PINTOS, Ana Elenara da Silva. Análise da experiência em monitoramento e avaliação de políticas públicas do Programa Esporte e Lazer da Cidade - PELC. 2017.189 f. Dissertação (Mestrado em Educação Física) - Universidade de Brasília, Brasília, 2017. 
SADER, Emir. A construção da hegemonia pós-neoliberal. SADER, Emir (Org.). 10 anos de governos pós-neoliberais no Brasil: Lula e Dilma. São Paulo: Boitempo; Rio de Janeiro: FLACSO Brasil, 2013.

SALVADOR, Evilasio. Financiamento tributário da política social no pós-Real. In. SALVADOR, Evilasio. Et al.. (Orgs.). Financeirização, fundo público e política social. São Paulo: Cortez, $2012^{\mathrm{a}}$. pp. 123-152.

SALVADOR, Evilasio. Fundo Público e o financiamento das Políticas Sociais no Brasil. Serv. Soc. Rev., Londrina, v. 14, n. 2, p. 04-22, jan./jun, 2012 b.

SENADO FEDERAL. SIGA Brasil. 2019. Disponível em: https://www12.senado.leg.br/orcamento/sigabrasil. Acesso em: 10 mar. 2019.

SENADO FEDERAL. Glossário. 2018. Disponível em: https://www12.senado.leg.br/orcamento/glossario. Acesso em: 26 abr. 2019.

SINGER. André. Será o lulismo um reformismo fraco? In: Os sentidos do lulismo: reforma gradual e pacto conservador. São Paulo: Companhia das Letras, 2012. Pp.169-221.

SINGER, André. Cutucando onças com varas curtas: o ensaio desenvolvimentista no primeiro mandato de Dilma Rousseff (2011-2014). Novos Estudos, São Paulo, n. 102, p. 43-71, jul. 2015.

STAREPRAVO, Fernando Augusto; MEZZADRI, Fernando Marinho; MARCHI JUNIOR, Wanderley. Criação e mudanças na estrutura do Ministério do Esporte do Brasil: tensões nas definições de espaços. RBEFE, São Paulo, v. 29, n. 2, p. 217-228, abr.jun. 2015.

TEIXEIRA, Marcelo Resende et al.. Esporte, fundo público e pequena política: os reveses de um orçamento ®emendado. Movimento, Porto Alegre, v. 24, n. 2, p. 593-606, abr./jun. 2018.

TEIXEIRA, Marcelo Resende et al.. O Programa Bolsa Atleta no contexto esportivo nacional. Motrivivência, Florianópolis, v. 29, n. esp., p. 92-109, dez. 2017.

TEIXEIRA, Marcelo Resende et al.. Política social de esporte e lazer no governo Lula: o Programa Esporte e Lazer da Cidade. Licere, Belo Horizonte, v. 17, n. 3, p. 134-161, set. 2014.

\section{NOTAS DE AUTOR}

AGRADECIMENTOS - Não se aplica.

CONTRIBUIÇÃO DE AUTORIA - Não se aplica.

FINANCIAMENTO - Não se aplica.

CONSENTIMENTO DE USO DE IMAGEM - Não se aplica. 
APROVAÇÃO DE COMITÊ DE ÉTICA EM PESQUISA - Não se aplica.

CONFLITO DE INTERESSES - Não se aplica.

\section{LICENÇA DE USO}

Os autores cedem à Motrivivência - ISSN 2175-8042 os direitos exclusivos de primeira publicação, com o trabalho simultaneamente licenciado sob a Licença Creative Commons Attribution Non-Comercial ShareAlike (CC BY-NC SA) 4.0 International. Estra licença permite que terceiros remixem, adaptem e criem a partir do trabalho publicado, desde que para fins não comerciais, atribuindo o devido crédito de autoria e publicação inicial neste periódico desde que adotem a mesma licença, compartilhar igual. Os autores têm autorização para assumir contratos adicionais separadamente, para distribuição não exclusiva da versão do trabalho publicada neste periódico (ex.: publicar em repositório institucional, em site pessoal, publicar uma tradução, ou como capítulo de livro), com reconhecimento de autoria e publicação inicial neste periódico, desde que para fins não comerciais e compartilhar com a mesma licença.

\section{PUBLISHER}

Universidade Federal de Santa Catarina. Programa de Pós-Graduação em Educação Física. LaboMídia - Laboratório e Observatório da Mídia Esportiva. Publicado no Portal de Periódicos UFSC. As ideias expressadas neste artigo são de responsabilidade de seus autores, não representando, necessariamente, a opinião dos editores ou da universidade.

\section{EDITORES}

Mauricio Roberto da Silva, Giovani De Lorenzi Pires, Rogério Santos Pereira.

\section{HISTÓRICO}

Recebido em: 05 de junho 2019.

Aprovado em: 17 de setembro 2019. 